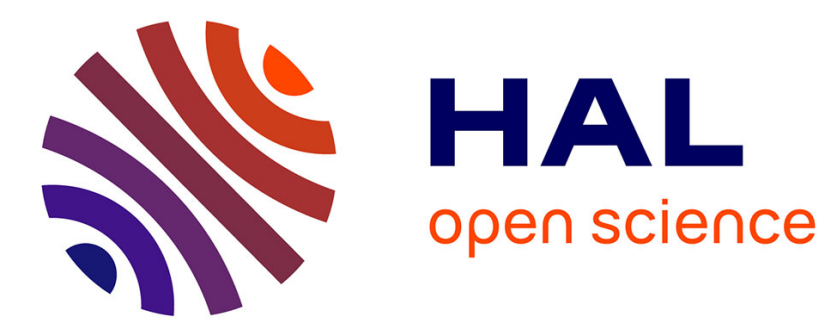

\title{
Excimer and Red Luminescence Due to Aggregation-Induced Emission in Naphthalene Based Zinc Phosphonate
}

Clarisse Bloyet, Jean-Michel Rueff, Julien Cardin, Vincent Caignaert, Jean-Louis Doualan, Jean-François Lohier, Paul-Alain Jaffres, Bernard Raveau

\section{To cite this version:}

Clarisse Bloyet, Jean-Michel Rueff, Julien Cardin, Vincent Caignaert, Jean-Louis Doualan, et al.. Excimer and Red Luminescence Due to Aggregation-Induced Emission in Naphthalene Based Zinc Phosphonate. European Journal of Inorganic Chemistry, 2018, 2018 (26), pp.3095-3103. 10.1002/ejic.201800369 . hal-01826146

\author{
HAL Id: hal-01826146 \\ https://hal.science/hal-01826146
}

Submitted on 12 Jul 2018

HAL is a multi-disciplinary open access archive for the deposit and dissemination of scientific research documents, whether they are published or not. The documents may come from teaching and research institutions in France or abroad, or from public or private research centers.
L'archive ouverte pluridisciplinaire HAL, est destinée au dépôt et à la diffusion de documents scientifiques de niveau recherche, publiés ou non, émanant des établissements d'enseignement et de recherche français ou étrangers, des laboratoires publics ou privés. 


\title{
Aggregation-Induced Emission
}

\section{Excimer and Red Luminescence Due to Aggregation-Induced Emission in Naphthalene Based Zinc Phosphonate}

\author{
Clarisse Bloyet, $^{[\mathrm{a}]}$ Jean-Michel Rueff, ${ }^{*[a]}{ }^{[a]}$ ulien Cardin, ${ }^{[\mathrm{b}]}$ Vincent Caignaert, $^{[\mathrm{a}]}$ \\ Jean-Louis Doualan, ${ }^{[\mathrm{b}]}$ Jean-François Lohier, ${ }^{[\mathrm{c}]}$ Paul-Alain Jaffrès, ${ }^{[\mathrm{d}]}$ and Bernard Raveau*[a]
}

\begin{abstract}
The phosphonate $\mathrm{Zn}\left(\mathrm{PO}_{3}-\mathrm{CH}_{2}-\mathrm{C}_{10} \mathrm{H}_{7}\right)$ has been obtained as single crystals and polycrystalline powder by hydrothermal synthesis from the parent acid 1-naphthylmethylphosphonic acid $\mathrm{H}_{2} \mathrm{PO}_{3} \mathrm{CH}_{2}-\mathrm{C}_{10} \mathrm{H}_{7}$. This $\mathrm{Zn}$ phosphonate exhibits a unique layered structure $\left(P 2_{1} / c\right)$, built up of single inorganic $\left[\mathrm{ZnPO}_{3} \mathrm{C}\right]$ layers stacked with organic bilayers of naphthylmethyl moieties " $\mathrm{CH}_{2}-\mathrm{C}_{10} \mathrm{H}_{7}$ ". The inorganic $\left[\mathrm{ZnPO}_{3} \mathrm{C}\right]$ layers consist of infinite zig-zag chains of corner-sharing $\mathrm{ZnO}_{4}$ tetrahedrons running along the $b$ direction and interconnected through $\mathrm{PO}_{3} \mathrm{C}$ tetrahedrons along $c$. The luminescence properties of this compound show two features never observed so far in any hybrid matrix containing naphthalene ligand: excimer emission characterized by one band fitted at $403 \mathrm{~nm}$; and red
\end{abstract}

\section{Introduction}

Numerous investigations of organic compounds with photoluminescence $(\mathrm{PL})$ properties have been carried out in the last two decades in view of developing modern technologies in photoelectronic devices, ${ }^{[1-4]}$ especially for organic light-emitting diodes (OLEDs). These organic materials mainly feature large $\pi$ systems; that is, aromatic molecules, or more exactly, dimeric species resulting from the association of a ground-state large molecule with an electronically excited one, called an excimer, ${ }^{[5,6]}$ as exemplified by the recent study of the PL properties of the naphthalene triplet excimer. ${ }^{[7]}$ Besides its crucial role to generate excimers for the realization of OLEDs, the triplet state is also studied for the generation of phosphorescence. The latter is of capital importance as a tool for spectroscopy in organic semiconductors, when it appears at room temperature. ${ }^{[8,9]}$

However, the applicability of these organic materials is limited by the difficulty to control the distances between the aryl

[a] Normandie Univ, ENSICAEN, UNICAEN, CNRS, CRISMAT, 14000 Caen, France

E-mail: jean-michel.rueff@ensicaen.fr bernard.raveau@ensicaen.fr http://www.crismat.ensicaen.fr

[b] Normandie Univ, ENSICAEN, UNICAEN, CNRS, CIMAP, 14000 Caen, France

[c] Normandie Univ, ENSICAEN, UNICAEN, CNRS, LCMT, 14000 Caen, France

[d] CEMCA UMR CNRS 6521, Université de Brest, IBSAM, 6 Avenue Victor Le Gorgeu, 29238 BREST, France

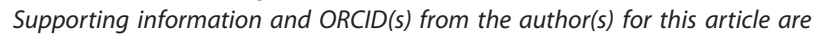
available on the WWW under https://doi.org/10.1002/ejic.201800369. luminescence, at room temperature, characterized by six bands fitted at 588, 611, 629, 667, 689, and $734 \mathrm{~nm}$. Comparison with the structure and luminescence properties of the parent phosphonic acid shows that these exceptional luminescence properties originate from particularly strong $\pi-\pi$ interactions, between the close-packed naphthalene rings with F2F and Lshaped conformations. The extremely fast decay of red emission ( $\tau \approx 50 \mathrm{~ns}$ ) shows that the latter is due to aggregationinduced emission (AIE), rather than to phosphorescence. The role of the inorganic $\left[\mathrm{ZnPO}_{3} \mathrm{C}\right]$ layers, which enhance the rigidity of the structure and restrict intramolecular motions, is also discussed to explain the appearance of the luminescence properties.

molecules, and their relative orientations, and by the lack of stability and rigidity of their frameworks. An attractive way to produce new photoluminescence properties is to associate a conjugated organic group with a transition element, as nicely shown for the large family of metal-organic frameworks (MOFs). ${ }^{[10]}$ In this respect, the $\mathrm{d}^{10}$ transition-metal $\left(\mathrm{Zn}^{\prime \prime}, \mathrm{Cd}^{\prime \prime}\right)$ complexes containing aryl ligands, the study of which was started more than thirty years ago, ${ }^{[11-13]}$ represent a huge source for the generation of PL properties. This is exemplified by recent studies, ${ }^{[14-21]}$ which show that PL originates from charge transfer between the $\pi$ ligands via the transition-metal cation. However, the rather low stability of such complexes limits their use.

Based on the above considerations, we believe that the very rich transition-metal phosphonate chemistry that has been developed these last thirty years ${ }^{[22-26]}$ offers a privileged route for the investigation of new PL properties, due to the great flexibility of these materials and to their high stability, compared with other hybrids. Zinc phosphonates containing aryl moieties may provide a potential source for the realization of luminescent materials, since $\mathrm{Zn}^{2+}$, due to its $\mathrm{d}^{10}$ electronic configuration, does not quench the fluorescence emission of aromatic rings. Nevertheless, the number of zinc phosphonates containing conjugated molecules or ligands that show PL properties ${ }^{[27-36]}$ is rather limited, and the relative role of each partner in this type of material (zinc or organic ligands) or the structural features (chemical bonding, etc.) is still a matter of debate. To gain insight into this complex issue, we have embarked on the investigation of zinc phosphonates containing a naphthalene based 
molecule, an aromatic ligand that has the advantage of being simple and that has been deeply investigated as molecular excimer. ${ }^{[6,7]}$ In the present article, we report on the structure and luminescence properties of a new and very simple layered $\mathrm{Zn}$ phosphonate, $\mathrm{Zn}\left(\mathrm{PO}_{3}-\mathrm{CH}_{2}-\mathrm{C}_{10} \mathrm{H}_{7}\right)$, involving 1-naphthylmethyl as an organic ligand. For the sake of comparison, the parent phosphonic acid, $\mathrm{H}_{2} \mathrm{PO}_{3}-\mathrm{CH}_{2}-\mathrm{C}_{10} \mathrm{H}_{7}$, was also investigated. We show that the $\mathrm{Zn}$ hybrid, which is very stable up to $400{ }^{\circ} \mathrm{C}$, exhibits both excimer and red luminescence (RL) at room temperature, which has not been observed, to date, for any naphthalene based hybrid.

\section{Results and Discussion}

\section{Phosphonic Acid $\mathrm{H}_{2} \mathrm{PO}_{3}-\mathrm{CH}_{2}-\mathrm{C}_{10} \mathrm{H}_{7}$ and Phosphonate $\mathrm{Zn}\left(\mathrm{PO}_{3}-\mathrm{CH}_{2}-\mathrm{C}_{10} \mathrm{H}_{7}\right)$ : Synthesis and Structure}

The 1-naphthylmethylzinc phosphonate $\mathrm{Zn}\left(\mathrm{PO}_{3}-\mathrm{CH}_{2}-\mathrm{C}_{10} \mathrm{H}_{7}\right)$, was hydrothermally synthesized in the form of polycrystalline samples from a solution of the commercial phosphonic acid $\mathrm{H}_{2} \mathrm{PO}_{3}-\mathrm{CH}_{2}-\mathrm{C}_{10} \mathrm{H}_{7}$ mixed with zinc nitrate. Single crystals of this compound (Figure S1, Supporting Information) were extracted from the batch and single crystals of the parent phosphonic acid were also grown for structure determination (Table 1). In contrast to the phosphonic acid which decomposes at $183^{\circ} \mathrm{C}$, the zinc phosphonate is stable up to $460{ }^{\circ} \mathrm{C}$ in air (see Exp. Sect. and Figure S2, Supporting Information).

Table 1. Single crystal data of $\mathrm{H}_{2} \mathrm{PO}_{3}-\mathrm{CH}_{2}-\mathrm{C}_{10} \mathrm{H}_{7}$ and $\mathrm{Zn}\left(\mathrm{PO}_{3}-\mathrm{CH}_{2}-\mathrm{C}_{10} \mathrm{H}_{7}\right)$ recorded at $150 \mathrm{~K}$.

\begin{tabular}{|l|l|l|}
\hline Formula & $\mathbf{H}_{\mathbf{2}} \mathbf{P O}_{\mathbf{3}}-\mathbf{C H}_{\mathbf{2}}-\mathbf{C}_{\mathbf{1 0}} \mathbf{H}_{\mathbf{7}}$ & $\mathbf{Z n}\left(\mathbf{P O}_{\mathbf{3}}-\mathbf{C H}_{\mathbf{2}}-\mathbf{C}_{\mathbf{1 0}} \mathbf{H}_{\mathbf{7}}\right)$ \\
\hline Formulas mass [g/mol] & 222.17 & 285.52 \\
\hline Space group & $P n a 2_{1}$ & $P 2_{1} / c$ \\
\hline$a[\AA ̊]$ & $8.003(2)$ & $19.4343(9)$ \\
\hline$b[\AA ̊]$ & $28.150(8)$ & $5.1680(3)$ \\
\hline$c[\AA ̊]$ & $4.5551(13)$ & $10.4851(5)$ \\
\hline$\alpha\left[^{\circ}\right]$ & 90 & 90 \\
\hline$\beta\left[^{\circ}\right]$ & 90 & $90.430(2)$ \\
\hline$\gamma\left[^{\circ}\right]$ & 90 & 90 \\
\hline$Z$ & 4 & 4 \\
\hline$V\left[\AA^{3}\right]$ & $1026.1(5)$ & $1053.1(1)$ \\
\hline$d_{\text {calc }}\left[\mathrm{g} / \mathrm{cm}^{3}\right]$ & 1.438 & 1.80081 \\
\hline$\mu\left[\mathrm{mm}{ }^{-1}\right]$ & 0.250 & 2.469 \\
\hline radiation source $\lambda[\AA ̊]$ & $M o-K_{\alpha} 0.71073$ & Mo- $K_{\alpha} 0.71073$ \\
\hline Pattern range $2 \theta\left[{ }^{\circ}\right]$ & $5.78-56.96$ & $6.29-60.064$ \\
\hline No. of reflections & 1966 & 3072 \\
\hline No. of soft constraints & 1 & 0 \\
\hline Weighted $R$ factor & 0.1796 & 0.0742 \\
\hline$R\left[F^{2}>2 \sigma\left(F^{2}\right)\right]$ & 0.0746 & 0.0340 \\
\hline$R_{\text {int }}$ (internal $R$ value) & 0.0259 & 0.0250 \\
\hline$S(G o o d n e s s$ of the fit) & 1.209 & 1.225 \\
\hline & & \\
\hline
\end{tabular}

The experimental conditions concerning the structure determination and refinements, as well as the atomic coordinates of these two compounds, are given in the Supporting Information (Tables ST1-ST3). Some structural features of the ligand $\mathrm{H}_{2} \mathrm{PO}_{3}-$ $\mathrm{CH}_{2}-\mathrm{C}_{10} \mathrm{H}_{7}$ and the organic moiety $\mathrm{PO}_{3}{ }^{2-}-\mathrm{CH}_{2}-\mathrm{C}_{10} \mathrm{H}_{7}$ of $\mathrm{Zn}\left(\mathrm{PO}_{3}-\mathrm{CH}_{2}-\mathrm{C}_{10} \mathrm{H}_{7}\right)$ are shown in Figure 1. Both exhibit, as expected, a very similar geometry of their naphthalene and tetrahedral $\mathrm{PO}_{3} \mathrm{C}$ groups, involving very close interatomic distances (Table ST3).

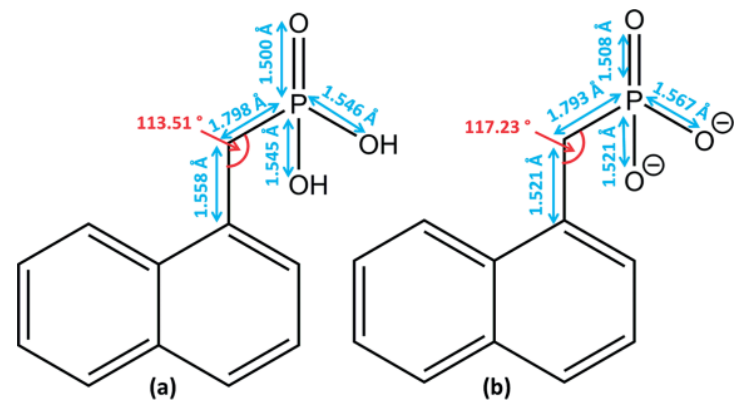

Figure 1. Geometric data relative to: (a) 1-naphthylmethylphosphonic acid $\mathrm{H}_{2} \mathrm{PO}_{3}-\mathrm{CH}_{2}-\mathrm{C}_{10} \mathrm{H}_{7}$; and (b) the organic moiety present in the phosphonate $\mathrm{Zn}\left(\mathrm{PO}_{3}-\mathrm{CH}_{2}-\mathrm{C}_{10} \mathrm{H}_{7}\right)$.

The analysis and comparison of these two structures show their rather similar layered character: they are both built up of organic bilayers involving the same phosphonate $\mathrm{PO}_{3}-\mathrm{CH}_{2}-$ $\mathrm{C}_{10} \mathrm{H}_{7}$ moieties (Figure 2). Those bilayers are parallel to the (010) plane in the $\mathrm{Pna2}_{1}$ structure of the parent phosphonic acid (Fig-

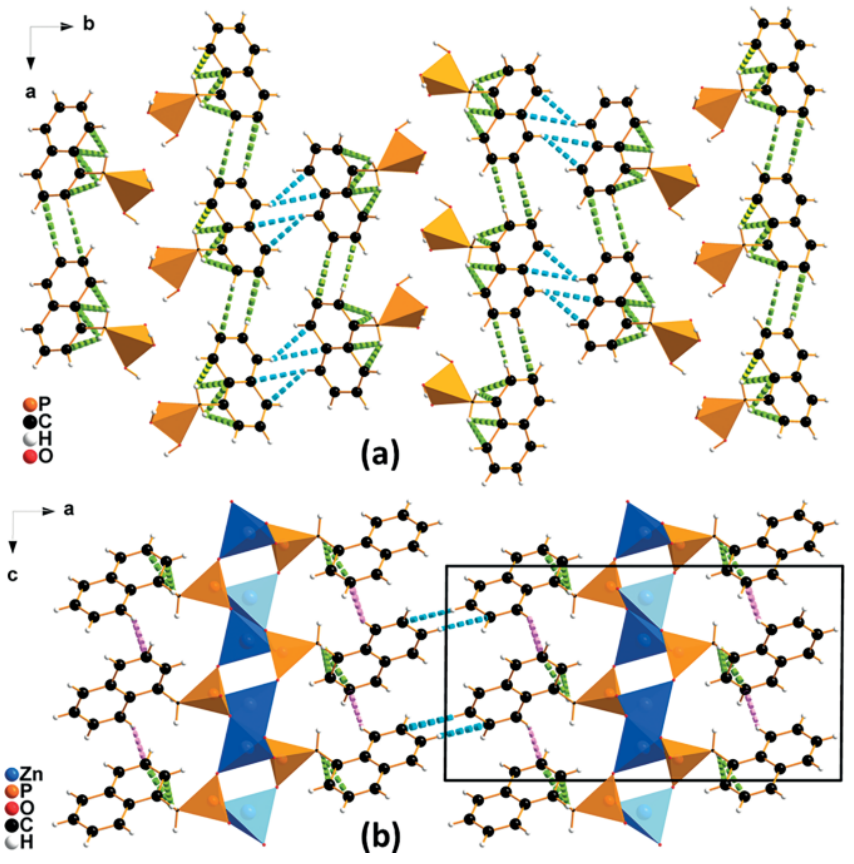

Figure 2. View of the structure of: (a) phosphonic acid $\mathrm{H}_{2} \mathrm{PO}_{3}-\mathrm{CH}_{2}-\mathrm{C}_{10} \mathrm{H}_{7}$ along $c$; and (b) zinc phosphonate $\mathrm{Zn}\left(\mathrm{PO}_{3}-\mathrm{CH}_{2}-\mathrm{C}_{10} \mathrm{H}_{7}\right)$ along the $b$ direction. Some $\mathrm{C} \cdot . . \mathrm{H}-\mathrm{C}$ interactions are represented on $\mathrm{H}_{2} \mathrm{PO}_{3}-\mathrm{CH}_{2}-\mathrm{C}_{10} \mathrm{H}_{7}$ and $\mathrm{Zn}\left(\mathrm{PO}_{3}-\right.$ $\mathrm{CH}_{2}-\mathrm{C}_{10} \mathrm{H}_{7}$ ): pink and green dashed lines correspond to naphthalene groups of the same organic column, with an angle of $84.27^{\circ}$ or parallel to each other, respectively; turquoise dashed lines correspond to ligands of two different organic layers, with an angle of $84.27^{\circ}$ for the zinc compound and an angle of $82.39^{\circ}$ for the organic molecule (see Table 2 ). 
ure $2 a$ ) and to the (100) plane in the $P 2_{1} / c$ structure of the zinc phosphonate (Figure $2 \mathrm{~b}$ ). In both structures, the cohesion between two successive organic layers is ensured by strong $\mathrm{C} . . . \mathrm{H}-\mathrm{C}$ hydrogen bonds between the aromatic ligands (see blue dotted lines Figure 2a-b and Table 2).

Table 2. $\mathrm{C} . . \mathrm{H}-\mathrm{C}$ hydrogen bonds within the structure of $\mathrm{Zn}\left[\mathrm{PO}_{3}-\mathrm{CH}_{2}-\mathrm{C}_{10} \mathrm{H}_{7}\right]$ and $\mathrm{C}_{10} \mathrm{H}_{7}-\mathrm{CH}_{2}-\mathrm{PO}(\mathrm{OH})_{2}$ with $\mathrm{C} . . . \mathrm{H}$ distances ranging from 2.7 to $3.3 \AA$ between the organic ligands (represented on Figure 1).

\begin{tabular}{|c|c|c|c|c|}
\hline \multirow{8}{*}{ 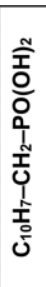 } & \multicolumn{4}{|c|}{$\begin{array}{l}\text { Intercolumnar } \mathrm{C} \cdots \mathrm{H}-\mathrm{C} \text { bonds between two tilted naphthalene } \\
\text { moieties with an angle of } 82.39^{\circ} \text { (turquoise dashed lines) }\end{array}$} \\
\hline & $\mathrm{C} 4 \cdots \mathrm{H} 6-\mathrm{C} 6$ & $2.910(9) \AA$ & $\mathrm{C} 5 \cdots \mathrm{H} 5-\mathrm{C} 5$ & $3.053(6) \AA$ \\
\hline & \multicolumn{4}{|c|}{$\begin{array}{c}\text { Intracolumnar C } \cdots \mathrm{H}-\mathrm{C} \text { bonds between two parallel naphtalene } \\
\text { moieties (green dashed lines) }\end{array}$} \\
\hline & $\mathrm{C} 10 \cdots \mathrm{H} 11 \mathrm{~B}-\mathrm{C} 11$ & $2.920(9) \AA$ & $\mathrm{C} 7 \cdots \mathrm{H} 3-\mathrm{C} 3$ & $3.163(9) \AA$ \\
\hline & $\mathrm{C} 1 \cdots \mathrm{H} 11 \mathrm{~B}-\mathrm{C} 11$ & $2.975(8) \AA$ & $\mathrm{C} 2 \cdots \mathrm{H} 11 \mathrm{~B}-\mathrm{C} 11$ & $3.190(9) \AA$ \\
\hline & $\mathrm{C} 10 \cdots \mathrm{H} 11 \mathrm{~A}-\mathrm{C} 11$ & $3.088(8) \AA$ & $\mathrm{C} 3 \cdots \mathrm{H} 7-\mathrm{C} 7$ & $3.194(9) \AA$ \\
\hline & $\mathrm{C} 9 \cdots \mathrm{H} 11 \mathrm{~A}-\mathrm{C}$ & $3.142(8) \AA$ & $\mathrm{C} 2 \cdots \mathrm{H} 8$ & $3.251(8) \AA$ \\
\hline & $\mathrm{C} 5 \cdots \mathrm{H} 11 \mathrm{~B}-\mathrm{C} 11$ & $3.158(7) \AA$ & $\mathrm{C} 8 \cdots \mathrm{H} 2-\mathrm{C} 2$ & $4(9) \AA$ \\
\hline \multirow{13}{*}{ 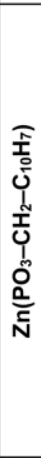 } & \multicolumn{4}{|c|}{$\begin{array}{c}\text { Intracolumnar } \mathrm{C} \cdots \mathrm{H}-\mathrm{C} \text { bonds between two tilted naphthalene } \\
\text { moieties with an angle of } 84.27^{\circ} \text { (pink dashed lines) }\end{array}$} \\
\hline & $\mathrm{C} 3 \cdots \mathrm{H} 7-\mathrm{C} 7$ & $2.765(3) \AA$ & $\mathrm{C} 2 \cdots \mathrm{H} 7-\mathrm{C} 7$ & $3.104(2) \AA$ \\
\hline & $\mathrm{C} 8 \cdots \mathrm{H} 4-\mathrm{C} 4$ & $2.938(3) \AA$ & $\mathrm{C} 7 \cdots \mathrm{H} 4-\mathrm{C} 4$ & $3.172(3) \AA$ \\
\hline & $\mathrm{C} 4 \cdots \mathrm{H} 8-\mathrm{C} 8$ & $2.946(3) \AA$ & $\mathrm{C} 10 \cdots \mathrm{H} 8-\mathrm{C} 8$ & $66(3) \AA$ \\
\hline & $\mathrm{C} 7 \cdots \mathrm{H}_{3}$ & 3.0 & $3-\mathrm{C} 1$ & (2) $\AA$ \\
\hline & $\mathrm{C} 5 \cdots \mathrm{H} 8-\mathrm{C} 8$ & $3.038(3) \AA$ & $\mathrm{C} 1 \cdots \mathrm{H} 3-\mathrm{C} 3$ & $3.222(2) \AA$ \\
\hline & $\mathrm{C} 6 \cdots \mathrm{H} 3-\mathrm{C} 3$ & $3.042(2) \AA$ & $\mathrm{C} 9 \cdots$ & $3.226(3) \AA$ \\
\hline & $\mathrm{C} 4 \cdots \mathrm{H} 7-\mathrm{C} 7$ & $3.047(3) \AA$ & & \\
\hline & \multicolumn{4}{|c|}{$\begin{array}{c}\text { Intracolumnar } \mathrm{C} \cdots \mathrm{H}-\mathrm{C} \text { bonds between two parallel naphthalene } \\
\text { moieties (green dashed lines) }\end{array}$} \\
\hline & $\mathrm{C} 2 \cdots \mathrm{H} 11 \mathrm{~A}-\mathrm{C} 11$ & $2.863(2) \AA$ & $\mathrm{C} 3 \cdots \mathrm{H} 11 \mathrm{~A}-\mathrm{C} 11$ & $2.876(3) \AA$ \\
\hline & \multicolumn{4}{|c|}{$\begin{array}{c}\text { Intercolumnar } \mathrm{C} \cdots \mathrm{H}-\mathrm{C} \text { bonds between two tilted naphthalene } \\
\text { moieties with an angle of } 84.27^{\circ} \text { (turquoise dashed lines) }\end{array}$} \\
\hline & $\mathrm{C} 8 \cdots \mathrm{H} 9-\mathrm{C} 9$ & $3.060(3) \AA$ & $\mathrm{C} 9 \cdots \mathrm{H} 9-\mathrm{C} 9$ & $3.255(4) \AA$ \\
\hline & $\mathrm{C} 9 \cdots \mathrm{H} 9-\mathrm{C} 9$ & $3.207(4) \AA$ & $\mathrm{C} 9 \cdots \mathrm{H} 8-\mathrm{C} 8$ & $3.260(3) \AA$ \\
\hline
\end{tabular}

In the phosphonic acid, the $\mathrm{PO}(\mathrm{OH})_{2} \mathrm{C}$ tetrahedral groups of the organic moieties are isolated from each other, but are displayed in the form of (010) layers, with hydrogen bonds within the layers (Figure 2a).

In the zinc phosphonate, infinite inorganic $\left[\mathrm{ZnPO}_{3}\right]$ layers parallel to the (100) plane form the basis of the structure (Figure $2 \mathrm{~b}$ ) and the methyl-naphthalene $\mathrm{CH}_{2}-\mathrm{C}_{10} \mathrm{H}_{7}$ ligands are grafted to these layers through the carbon atom of their $\mathrm{CH}_{2}$ group. Thus, the structure can be described by the stacking along $a$ of the $\left[\mathrm{ZnPO}_{3} \mathrm{C}\right]$ layers, alternating with the methyl naphthalene $\mathrm{CH}_{2}-\mathrm{C}_{10} \mathrm{H}_{7}$ bilayers. Moreover, the $\left[\mathrm{ZnPO}_{3} \mathrm{C}\right]$ layers (Figure $3 \mathrm{a}$ ) can be described as infinite zig-zag chains of cornersharing $\mathrm{ZnO}_{4}$ tetrahedrons running along the $b$ direction. These chains are interconnected through $\mathrm{PO}_{3} \mathrm{C}$ tetrahedrons along $\mathrm{c}$ : each $\mathrm{ZnO}_{4}$ tetrahedron shares two apices with two $\mathrm{PO}_{3} \mathrm{C}$ tetrahedrons and two other apices with four polyhedrons (two $\mathrm{PO}_{3} \mathrm{C}$ and two $\mathrm{ZnO}_{4}$ tetrahedrons) (Figure S3c). Compared with other phosphonates containing a metal ion with a tetrahedral coordination, ${ }^{[37]}$ and to $\mathrm{Zn}$-phosphonate containing conjugated molecules or ligands, ${ }^{[27-36]}$ this layered structure is unique, due to the fact that strong infinite " $\mathrm{Zn}-\mathrm{O}-\mathrm{Zn}$ " and " $\mathrm{Zn}-\mathrm{O}-\mathrm{P}-\mathrm{O}-\mathrm{Zn}$ " ionocovalent bonds are observed along $b$ and along $b$ and $c$, respectively, within the inorganic layers.

As a consequence, those $\mathrm{Zn}$ phosphonate layers are much more stable and are extremely rigid, compared with the layers of isolated $\mathrm{PO}(\mathrm{OH})_{2} \mathrm{C}$ tetrahedrons in the phosphonic acid, the cohesion of which is only ensured by hydrogen bonds.

Finally, it is worth pointing out that in the Zn phosphonate, the naphthylmethyl moieties are strongly connected to the

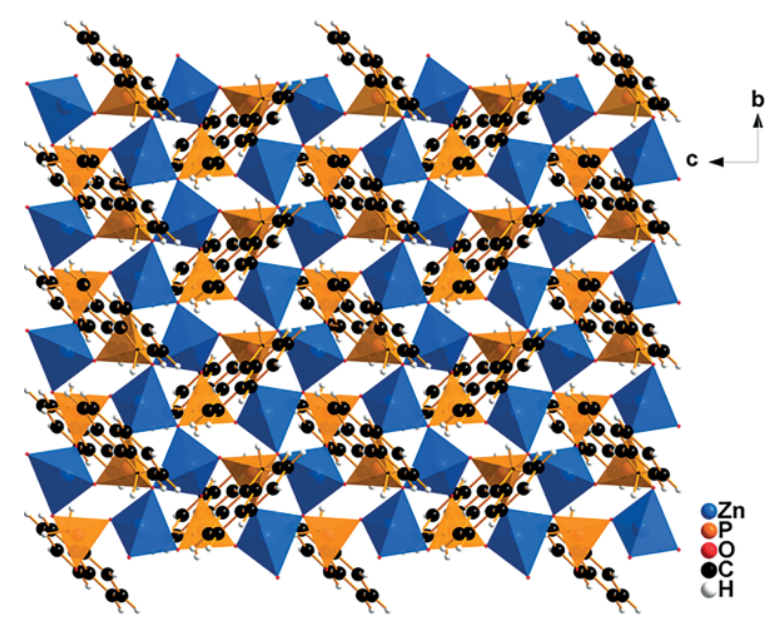

(a)

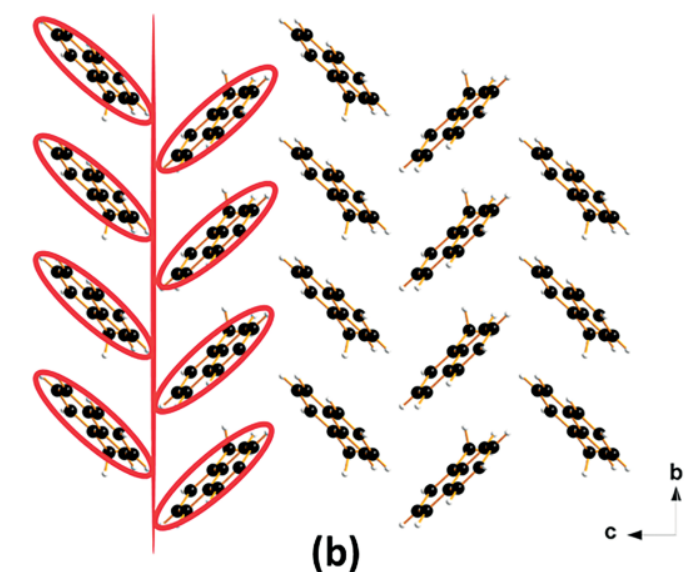

Figure 3. (a) Projection of one layer of $\mathrm{Zn}\left(\mathrm{PO}_{3}-\mathrm{CH}_{2}-\mathrm{C}_{10} \mathrm{H}_{7}\right)$ along a. (b) The herringbone arrangement of the naphthalene groups with an angle of $84.27^{\circ}$.

$\left[\mathrm{ZnPO}_{3} \mathrm{C}\right]$ layers, forming a herringbone pattern (Figure $3 \mathrm{~b}$ ). However, $\mathrm{Zn}^{2+}$ is not chemically bonded to the hydrocarbon moieties, as will be discussed for the interpretation of the luminescence properties of this compound.

\section{Luminescence Properties}

The UV/Vis absorbance spectra of the phosphonic acid $\mathrm{H}_{2} \mathrm{PO}_{3}-$ $\mathrm{CH}_{2}-\mathrm{C}_{10} \mathrm{H}_{7}$ and of the zinc phosphonate $\mathrm{Zn}\left(\mathrm{PO}_{3}-\mathrm{CH}_{2}-\mathrm{C}_{10} \mathrm{H}_{7}\right)$ (Figure 4) show absorption bands ranging from $320 \mathrm{~nm}$ to the deep UV. Those absorption bands are due to the presence of naphthalene moieties in both compounds. Indeed, naphthalene is known for its strong absorption bands, ranging from 211 to $319 \mathrm{~nm}$, observed either in solution or the solid (crystalline) form. ${ }^{[38]}$ Among these bands, some are attributed to several singlet transitions of naphthalene, S0 $\rightarrow$ S1 $(290-320 \mathrm{~nm})$, $\mathrm{S} 0 \rightarrow$ S2 $(240-290 \mathrm{~nm})$, and S0 $\rightarrow$ S3 $(200-230 \mathrm{~nm})$.

The similarity in the absorbance spectra between phosphonic acid and zinc phosphonate testifies to the fact that the main mechanism of absorption is driven by their common organic part.

The observed bands clearly overlap with the electronic absorption bands reported for naphthalene, which range from 


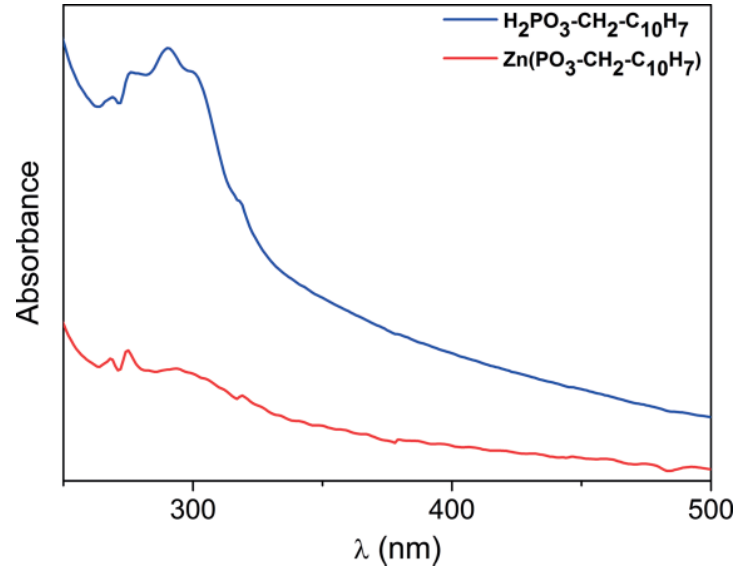

Figure 4. Normalized absorbance spectra of 1-naphthylmethylphosphonic acid $\mathrm{H}_{2} \mathrm{PO}_{3}-\mathrm{CH}_{2}-\mathrm{C}_{10} \mathrm{H}_{7}$ (dark blue line) and the $\mathrm{Zn}\left(\mathrm{PO}_{3}-\mathrm{CH}_{2}-\mathrm{C}_{10} \mathrm{H}_{7}\right)$ phosphonate (red line), obtained from specular transmittance measurement.

333 to $189 \mathrm{~nm}$ in the gas phase $\mathrm{e}^{[39-42]}$ and from 320 to $212 \mathrm{~nm}$ in the solid phase. ${ }^{[43-47]}$ Thus, these spectra correspond to a major contribution of the naphthalene part to the absorption in both compounds, the phosphonic acid and the zinc phosphonate.

The emission luminescence spectra of 1-naphthylmethylphosphonic acid $\mathrm{H}_{2} \mathrm{PO}_{3}-\mathrm{CH}_{2}-\mathrm{C}_{10} \mathrm{H}_{7}$ and the zinc phosphonate $\mathrm{Zn}\left(\mathrm{PO}_{3}-\mathrm{CH}_{2}-\mathrm{C}_{10} \mathrm{H}_{7}\right)$, in the $300-500 \mathrm{~nm}$ wavelength range, are shown in Figure 5 . The phosphonic acid spectrum is mainly characterized by an intense peak around $350 \mathrm{~nm}$, followed by a small peak at $410 \mathrm{~nm}$, whereas the $\mathrm{Zn}$ phosphonate shows two large peaks of about the same intensity around similar wavelengths; that is, ca. 360 and $420 \mathrm{~nm}$, respectively. In fact, the emission in both compounds can be fitted by three bands called 1, 2, and 3, by means of Voigt functions (dashed color lines on Figure 5). The spectral positions of the 1, 2, and 3 bands (inset Figure 5) are very close in the two compounds: $348 \mathrm{~nm}$ (3.56 eV), $368 \mathrm{~nm}(3.37 \mathrm{eV})$, and $415 \mathrm{~nm}(2.99 \mathrm{eV})$ in the phosphonic acid against $346 \mathrm{~nm}(3.58 \mathrm{eV}), 364 \mathrm{~nm}(3.41 \mathrm{eV})$, and $403 \mathrm{~nm}$ (3.08 eV) in the $\mathrm{Zn}$ phosphonate. This spectral similarity between the two compounds evidences a common origin of those emission bands identified from previous studies ${ }^{[38]}$ as naphthalene based fluorescence, corresponding to the recombination that occurs from $\pi^{*}$ excited states modulated by vibrionic coupling. Grabner et al. ${ }^{[48]}$ have indeed reported naphthalene singlet-singlet recombination fluorescence ranging from 310 to $390 \mathrm{~nm}$, and have shown, in some favorable conditions of the saturated solution, naphthalene excimer-type emission ranging from 375 to $420 \mathrm{~nm}$. Thus, the bands located at $403 \mathrm{~nm}$ and $415 \mathrm{~nm}$ do show a structural characteristic of broad-band excimer typical emission, due to interacting naphthalene components in a $\pi$-stacked array. Therefore, considering the $300-$ $500 \mathrm{~nm}$ spectral range, these results show that both compounds exhibit a singlet-singlet fluorescence and strongly suggest the existence of an excimer fluorescence that is strongly enhanced in the $\mathrm{Zn}$ phosphonate, compared with the phosphonic acid. This different behavior between the two compounds will be discussed further in the section relative to the relationships between structure and luminescence.

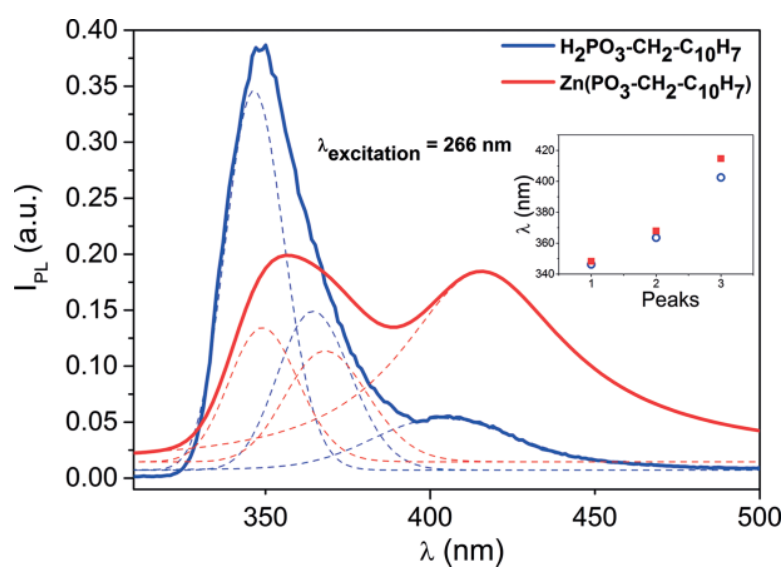

Figure 5. Photoluminescence spectra of 1-naphthylmethylphosphonic acid $\mathrm{H}_{2} \mathrm{PO}_{3}-\mathrm{CH}_{2}-\mathrm{C}_{10} \mathrm{H}_{7}$ (dark blue line) and the $\mathrm{Zn}\left(\mathrm{PO}_{3}-\mathrm{CH}_{2}-\mathrm{C}_{10} \mathrm{H}_{7}\right)$ hybrid compound (red line). For both compounds, the dashed lines correspond to the several bands of emission that were highlighted using Voigt functions. Inset: Representation of the bands of emission versus the wavelength for both compounds.

Measurements performed on a longer wavelength range, from 500 to $800 \mathrm{~nm}$ (Figure 6) and on a comparable amount of matter show that both compounds exhibit surprisingly red luminescence. Importantly, the Zn phosphonate shows intense luminescence (red curve Figure 6, Figure S6a), characterized by two well-defined peaks at around 615 and $660 \mathrm{~nm}$, two large peaks around 580 and $740 \mathrm{~nm}$, and slope variations around 630 and $680 \mathrm{~nm}$. This spectrum can be fitted with six bands located at $588 \mathrm{~nm}(2.11 \mathrm{eV}), 611 \mathrm{~nm}(2.02 \mathrm{eV}), 629 \mathrm{~nm}(1.97 \mathrm{eV}), 667 \mathrm{~nm}$ $(1.86 \mathrm{eV}), 689 \mathrm{~nm}(1.80 \mathrm{eV})$, and $734 \mathrm{~nm}(1.69 \mathrm{eV})$ (reported in the inset of Figure 6). In contrast, the luminescence of phosphonic acid in this wavelength range is weak; that is, more than one order of magnitude smaller (blue curve Figure 6), and only two bands can be identified at $617 \mathrm{~nm}(2.01 \mathrm{eV})$ and $670 \mathrm{~nm}$ $(1.85 \mathrm{eV})$. The enlarged curves of the phosphonic acid (see Figure S6b) do not allow further bands to be detected, but the wavelength values of these bands, which are very close to those of the two main intense bands of the $\mathrm{Zn}$ phosphonate (inset Figure 6), clearly indicate that the phosphonic acid exhibits the same type of luminescence, with the "lost bands" of this compound having intensities below our detection threshold level. The origin of the emission fine structure between 600 and $750 \mathrm{~nm}$ may be attributed to modulation by vibrionic coupling, due to vibrational bands/levels originating from $\mathrm{C}-\mathrm{C}$ stretching and/or $\mathrm{C}-\mathrm{H}$ in-plane bending on benzene-ring modes. ${ }^{[49]}$ This strongly suggests that these luminescence bands also originate from the naphthalene based ligands. Moreover, bearing in mind from the structure that the $d^{10}$ cation $\mathrm{Zn}^{2+}$ is not directly connected to the naphthalene rings, no ligand-to-metal or metalto-ligand charge transfer (LMCT or MLCT) can be invoked to explain the appearance of such intense red bands in the $\mathrm{Zn}$ phosphonate.

At this point of the investigations, the possibility of attributing the $490-740 \mathrm{~nm}$ structured bands to phosphorescence from triplet states originating from naphthalene based ligands must be considered. Such a statement is supported by the fact that phosphorescence emission from 450 to $650 \mathrm{~nm}$ has been re- 


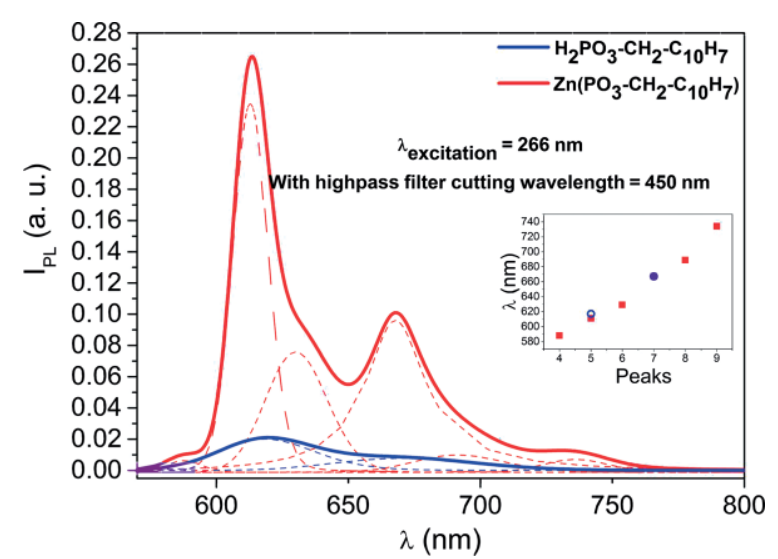

Figure 6. Photoluminescence spectra of 1-naphthylmethylphosphonic acid $\mathrm{H}_{2} \mathrm{PO}_{3}-\mathrm{CH}_{2}-\mathrm{C}_{10} \mathrm{H}_{7}$ (dark blue line) and $\mathrm{Zn}\left(\mathrm{PO}_{3}-\mathrm{CH}_{2}-\mathrm{C}_{10} \mathrm{H}_{7}\right)$ hybrid compound (red line). For both compounds, the dashed lines correspond to the several bands of emission that were highlighted using Voigt functions. Inset: Representation of the bands of emission versus the wavelength for both compounds.

ported for naphthalene solution frozen at $77 \mathrm{~K}_{,}^{[50]}$ from 480 to $600 \mathrm{~nm}$ at room temperature for naphthalene derivatives in liquid phase, ${ }^{[9,51]}$ and from 475 to $700 \mathrm{~nm}$ for tethered naphthalene moieties in zeolites. ${ }^{[52]}$

Photoluminescence excitation (PLE) measurements were then performed for $\mathrm{Zn}\left(\mathrm{PO}_{3}-\mathrm{CH}_{2}-\mathrm{C}_{10} \mathrm{H}_{7}\right)$ to elucidate the excitation mechanism of this emission. PLE spectra obtained at detection wavelengths of 611,623 , and $667 \mathrm{~nm}$ (Figure 7) show decreasing intensity with increasing wavelength, with a threshold fall in excitability for excitation with wavelengths lower than $320 \mathrm{~nm}$. This behavior has to be put into perspective with the absorption measurement (Figure 4).

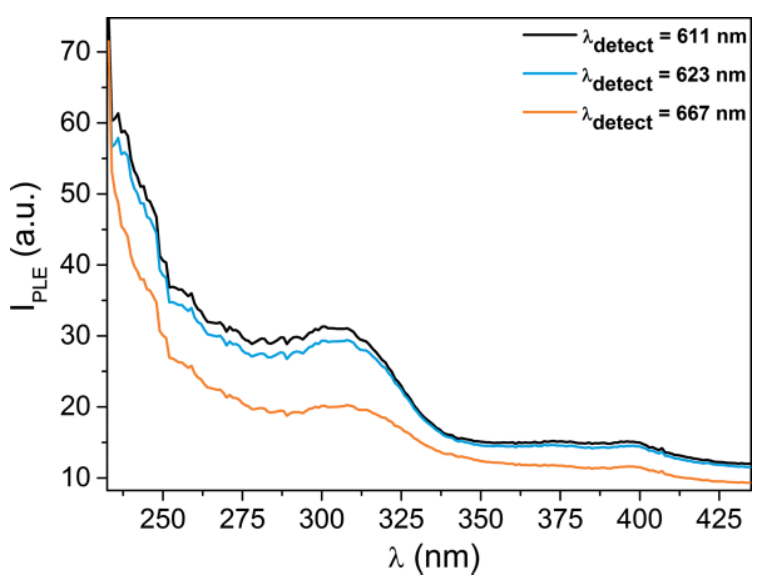

Figure 7. Photoluminescence excitation (PLE) spectra of $\mathrm{Zn}\left(\mathrm{PO}_{3}-\mathrm{CH}_{2}-\mathrm{C}_{10} \mathrm{H}_{7}\right)$ obtained at different wavelengths: $611 \mathrm{~nm}, 623 \mathrm{~nm}$, and $667 \mathrm{~nm}$.

Indeed, the similarity of the shape suggests that the excitation of red emission is mainly mediated by the excitation of singlet states at shorter wavelengths. Moreover, the lack of bands for wavelengths larger than $320 \mathrm{~nm}$ suggests that 490-740 nm luminescence bands are not allowed for direct excitation, which is in favor of the existence of phosphorescence triplet states.
To further investigate this red emission, time-decay measurements were performed on samples at different wavelengths of detection $(365,402,415,618,670 \mathrm{~nm})$, under excitation at $266 \mathrm{~nm}$, for comparison with continuous-wave PL spectroscopy.

As shown in Figure S7, the obtained spectra were fitted using two different models: a time-decay single exponential [Equation (a)] and an average time decay [Equation (b)]:

(a) $\mathrm{I}_{\mathrm{PL}}=\mathrm{I}_{\mathrm{PL} 0} \cdot \mathrm{e}^{\frac{-\mathrm{t}}{\tau}}$ with $\tau$ representing the single exponential model lifetime

(b) $\left\langle\tau>=\frac{\int_{0}^{\infty} I_{\mathrm{PL}}(\mathrm{t}) \mathrm{dt}}{\mathrm{I}_{\mathrm{PL} 0}}\right.$ with $\tau$ representing the average time decay.

Firstly, both time-decay models lead to comparable results (Table ST4). Secondly, taking into account the instrumental response function (IRF) allows the determination of the measurement-system time response of about 14 ns.

In the short-wavelength range (350-400 nm), both compounds possess a decay time equal to, or below, the measurement-system time response ( $\tau \leq 14 \mathrm{~ns}$ ), whereas in the longer wavelength range (500-800 $\mathrm{nm})$, the zinc phosphonate has a significantly longer time decay, ranging from 40 to 65 ns, while the decay time of the phosphonic acid remains below, or equal to, 14 ns. This decay time found at short wavelengths for fluorescence and excimer emission is consistent with values previously observed. ${ }^{[53,54]}$ In contrast, for the longer wavelength range (500-800 $\mathrm{nm}$ ), a small value of the decay time, of about $50 \mathrm{~ns}$, of the red emission is observed for the $\mathrm{Zn}$ phosphonate, compared with the typical values of $10^{-4}-10^{-3} \mathrm{~s}$ reported for the phosphorescence decay time in naphthalene based materials. ${ }^{[55]}$ This extremely low $\tau$ value suggests that, at room temperature, either dominant phonon-assisted nonradiative loss mechanisms strongly quench the phosphorescence or that this red emission does not originate from the recombination of a triplet state and cannot be described as phosphorescence. This point will be discussed in the next section.

\section{Role of Structure and Chemical Bonding in the Luminescence Properties}

The exceptional luminescence properties of the $\mathrm{Zn}$ phosphonate, compared with the phosphonic acid, involving a much higher intensity of the excimer and red emission bands at room temperature, strongly suggest that the relative orientations of the naphthalene ligands with respect to each other and the interligand $\mathrm{C}-\mathrm{H} . . . \mathrm{C}$ bonds play a crucial role in those properties. Detailed studies carried out in MOFs by McManus et al. ${ }^{[56,57]}$ have indeed shown that the formation of exciplexes or excimers in these systems originates from $\pi-\pi$ interactions and depends on the nature of the latter; in particular, on the relative orientations of the aromatic rings, with a privileged effect of the faceto-face (F2F) and edge-to-face (L-shaped) conformations (see Scheme 1) upon the red emission. It has also been shown that the separation distances and angles between the ring planes play a crucial role. ${ }^{[7,10,58]}$ 


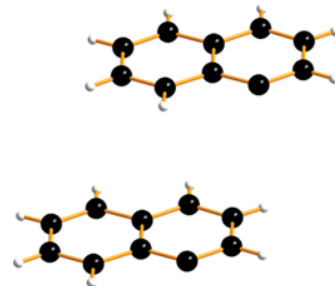

Face-to-face

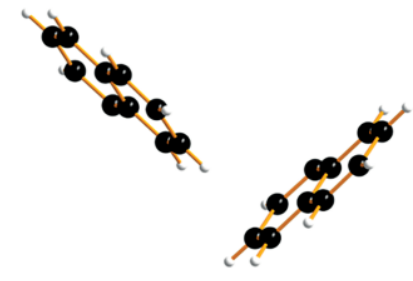

L-shaped $90^{\circ}$
Scheme 1. The configurations of naphthalene rings observed in this work.

The arrangements of the naphthalene moieties within a single organic layer in the two structures, using the space filling representation (Figure 8 ), clearly explain the much higher ability of the $\mathrm{Zn}$ phosphonate to produce an excimer emission.

In the parent phosphonic acid (Figure 8a), the naphthalene rings exhibit a one-dimensional F2F arrangement, parallel to [001], with interplanar distances between 3.4 and $3.5 \AA$. The $\mathrm{C}-\mathrm{H}$...C distances between two successive rows range from 2.92 to $3.27 \AA$. These characteristics are quite compatible with the formation of an excimer, as reported by Forster et al., with intermolecular distances ranging from 3.00 to $3.60 \AA .{ }^{[59]}$ However, the successive rows are isolated from each other along $a$. In the zinc phosphonate, the naphthalene rings have their plane perpendicular to the inorganic layer, forming a herringbone configuration (Figure 3). Moreover, the angle between two successive naphthalene planes along $c$ is close to $90^{\circ}\left(84.27^{\circ}\right)$. It results in a quite exceptional arrangement of the naphthalene rings within each single organic (100) layer (Figure 8b), corresponding to a combination of F2F rows running along $b$, with $90^{\circ} \mathrm{L}$-shaped rows running along $c$. This type of orientations of the naphthalene rings with respect to each other implies that each ring forms two F2F and four L-shaped interactions with its six neighbors.

The interplanar distances between the rings along $b$, of $3.47 \AA$, as well as the minimum $\mathrm{C}-\mathrm{H}$...C distances within the F2F rows, of 2.86-2.88 $\AA$, and between two rings with an Lshaped configuration, of $2.76 \AA$, along c (see Table 2, Figure 2 for more detailed analysis) show that the close-packed assemblage of the naphthalene rings imposes strong $\pi-\pi$ and $\mathrm{C}-\mathrm{H} \cdots \pi$ interactions. Remarkably, a similar arrangement of those rings is observed at the interface between the two organic layers (Figure 8c).

Such concomitant and three-dimensional, strong F2F and Lshaped interactions have been previously observed in naphthalene diimide ditosylate. ${ }^{[60]}$

The study of the Hirshfeld surface (HS) and of the corresponding 2D fingerprint plots ${ }^{[61,62]}$ (see Supporting Information, Figures S4 and S5) supports the above statements. It shows that the $\mathrm{C} \cdots \mathrm{H}$ interactions between the naphthalene rings are significantly more numerous (30\%) for the $\mathrm{Zn}$ phosphonate than for the phosphonic acid (25\%) and evidences specific $\pi \cdots \pi$ stacking in the $\mathrm{Zn}$ phosphonate.

This analysis of the structure and chemical bonding explains the appearance of excimer bands at 403-415 nm for these two compounds and the much larger intensity of this emission for the $\mathrm{Zn}$ phosphonate. In contrast, the origin of red emission at room temperature in the latter material is not obvious. Bearing in mind the effect of molecular packing upon luminescence, previously shown by Q. Li and Z. $\mathrm{Li}^{\left[{ }^{[63]}\right.}$ two possible phenomena have to be considered: room temperature phosphorescence (RTP) and aggregation-induced emission (AIE).

For pure naphthalene, strong phosphorescence is only observed below $77 \mathrm{~K}$ and becomes shallow at room temperature, ${ }^{[64]}$ whereas naphthalene included in a zeolite framework $^{[65]}$ exhibits RTP, but in a lower wavelength range than the present $\mathrm{Zn}$ phosphonate. Moreover, as stated above, the lifetime of the latter, of $50 \mathrm{~ns}$, is several orders of magnitude smaller than that usually observed for phosphorescence in naphthalene and derivatives (ca. ms). Although recent studies of aryl based organic molecules have shown that rigidification of the structure and interactions of the aryl ligands with molecules of the same type (self-aggregation) can induce phosphorescence, ${ }^{[66]}$ all of these features suggest that this red emission does not originate from RTP.

The red emission of the $\mathrm{Zn}$ phosphonate shows great similarities with the remarkable fluorescence properties previously reported for naphthalene imide and diimide derivatives. ${ }^{[60,67-70]}$ One indeed observes that the $\mathrm{Zn}$ phosphonate bands are close to those observed for these compounds, and importantly, that its red emission lifetime of $50 \mathrm{~ns}$ is of the same order of magnitude as that of the naphthalene diimide derivatives (ranging

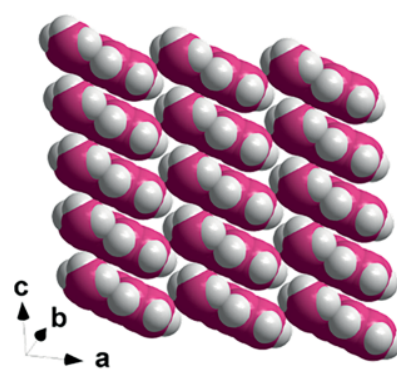

(a)

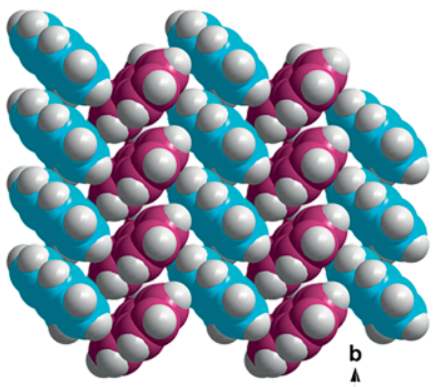

(b) $\mathrm{c} 4$

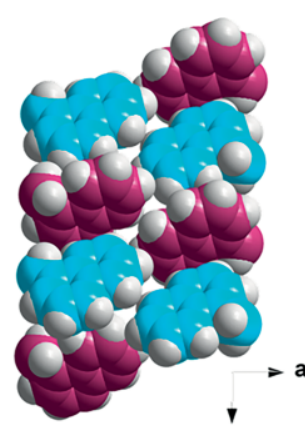

(c) $\mathrm{c}$

Figure 8. Space filling representation of naphthalene rings in single organic layers of: (a) 1-naphthylmethylphosphonic acid, view along the aromatic plane; and (b) zinc phosphonate, view along $a$. (c) Double layer of zinc phosphonate, view along $b$. The blue and plum colors represent the carbon atoms of the naphthalene rings with two different orientations, while grey is used for hydrogen atoms. 
from $45 \mathrm{ps}^{[67]}$ to ca. $32.6 \mathrm{~ns}^{[70]}$; that is, much smaller than the value observed usually for phosphorescence of naphthalene derivatives. In fact, this kind of luminescence has been shown by previous authors to be related to aggregation-induced emission (AIE). ${ }^{[63,71,72]}$ The latter is due to radiative recombination occurring from delocalized states; that is, from strong $\pi-\pi$ interactions between a large number of naphthalene rings, ${ }^{[68,73]}$ and it is strongly dependent on their packing and rigidity. ${ }^{[63,71]}$

Thus, the exceptional close packing and proximity of the naphthalene based ligands, with combined F2F and L-shaped configurations forming infinite layers in the $\mathrm{Zn}$ phosphonate, significantly enhance the electronic charge transfer interactions. They favor the appearance of AIE, and consequently, explain this red emission enhancement. The presence of the $\left[\mathrm{ZnPO}_{3} \mathrm{C}\right]$ layers that form strong ionocovalent bonds, and consequently, dramatically rigidify the structure, blocking the phonons, also plays a crucial role in the appearance of this AIE.

From this study, a schematic representation of the electronic energy levels for both the phosphonic acid and the phosphonate $\mathrm{Zn}\left(\mathrm{PO}_{3}-\mathrm{CH}_{2}-\mathrm{C}_{10} \mathrm{H}_{7}\right)$, with possible energetic paths, is presented in Figure 9.

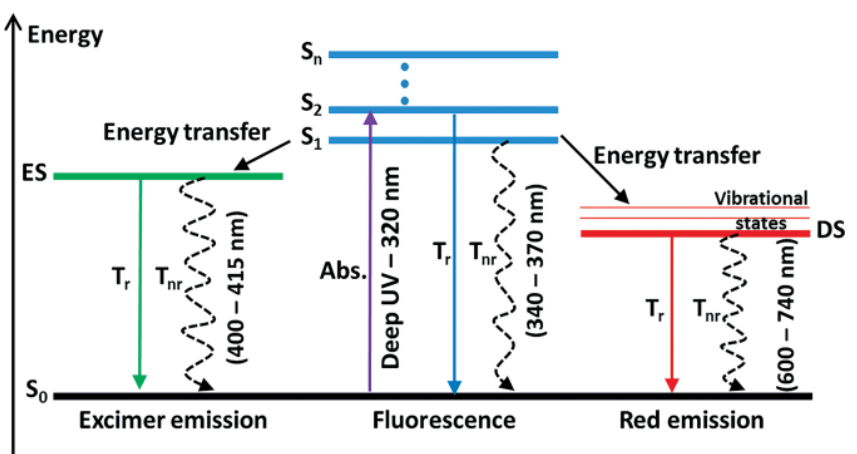

Figure 9. Electronic energy-level diagrams of the $\mathrm{H}_{2} \mathrm{PO}_{3}-\mathrm{CH}_{2}-\mathrm{C}_{10} \mathrm{H}_{7}$ and $\mathrm{Zn}\left(\mathrm{PO}_{3}-\mathrm{CH}_{2}-\mathrm{C}_{10} \mathrm{H}_{7}\right)$ compounds, with singlet (S), triplet $(\mathrm{T})$, and excimer states; absorption rate (abs); radiative $\left(\mathrm{T}_{\mathrm{r}}\right)$ and nonradiative $\left(\mathrm{T}_{\mathrm{nr}}\right)$ transitions; and delocalized states (DS).

This figure presents the excitation path of both compounds at $266 \mathrm{~nm}$. The direct nonradiative and radiative recombination, leading to short-wavelength-range (340-370 nm) observed photoluminescence, is associated with naphthalene based fluorescence, due to recombination between singlet states (S). Excimer emission due to $\pi$ stacking is represented and leads to emission of a broad structureless band at around $400 \mathrm{~nm}$ in both the phosphonic acid and the $\mathrm{Zn}$ phosphonate. The longerwavelength-range luminescence is attributed to recombination from manifold vibrational delocalized states (DS) induced by close packing and proximity of the naphthalene moieties and vibrational modes of $\mathrm{C}-\mathrm{C}$ and $\mathrm{C}-\mathrm{H}$ bonding.

The difference in the time decay observed at longer wavelengths (red emission) between the two compounds evidences a modification of the rates of the radiative and nonradiative mechanisms occurring in the system. Assuming that the nature of the energy transfer remains the same, a reduction of the nonradiative rate from this long-wavelength-range radiative recombination may explain the increase in the decay time for the $\mathrm{Zn}$ phosphonate. The strong reinforcement of the rigidity of the $\mathrm{Zn}$ phase structure, with respect to the phosphonic acid mentioned above, contributes to this reduction of phononassisted nonradiative losses, and therefore, induces a dramatic enhancement of the red emission.

\section{Conclusion}

This study reports the synthesis of a new zinc phosphonate $\mathrm{Zn}\left(\mathrm{PO}_{3}-\mathrm{CH}_{2}-\mathrm{C}_{10} \mathrm{H}_{7}\right)$, whose inorganic " $\mathrm{ZnPO} \mathrm{P}_{3} \mathrm{C}$ " layers and organic 1-naphthylmethyl bilayers form a very close-packed and rigid framework, in contrast to most of the hybrids containing conjugated molecules that have been studied to date. In this structure, the specific F2F and L-shaped arrangements of the naphthalene rings, and their great proximity, generate strong $\pi-\pi$ interactions. The excimer fluorescence and the red emission of this compound originate from these strong interactions and are enhanced by the rigidity of the structure. These results pave the way for the investigation of phosphonates containing various naphthalene based ligands, as well as other conjugated ligands, such as anthracene, with a view to producing new luminescence properties and understanding their mechanism. The high stability of this phosphonate is also encouraging for future applications in organic electronics. ${ }^{[74,75]}$

\section{Experimental Section}

\section{X-ray Diffraction and Structure Determination}

Suitable single crystals of $\mathrm{H}_{2} \mathrm{PO}_{3}-\mathrm{CH}_{2}-\mathrm{C}_{10} \mathrm{H}_{7}$ and $\mathrm{Zn}\left(\mathrm{PO}_{3}-\mathrm{CH}_{2}-\right.$ $\mathrm{C}_{10} \mathrm{H}_{7}$ ) were selected from their pure batches. Then, $\mathrm{X}$-ray diffraction characterizations were performed at $150 \mathrm{~K}$ with a Bruker Nonius Kappa CCD area-detector diffractometer with graphite-monochromated Mo- $K_{\alpha}$ radiation $(\lambda=0.71073 \AA)$. Program used to solve the structures: SHELXS-97. ${ }^{[76]}$ Program used to refine structures: SHELXL-2014. ${ }^{[76]}$

CCDC 1579362 (for $\left.\mathrm{H}_{2} \mathrm{PO}_{3}-\mathrm{CH}_{2}-\mathrm{C}_{10} \mathrm{H}_{7}\right)$, and 1579363 [for $\mathrm{Zn}\left(\mathrm{PO}_{3}-\right.$ $\left.\mathrm{CH}_{2}-\mathrm{C}_{10} \mathrm{H}_{7}\right)$ ] contain the supplementary crystallographic data for this paper. These data can be obtained free of charge from The Cambridge Crystallographic Data Centre.

Thermogravimetric Analysis: The thermogravimetric analysis was carried out on a polycrystalline sample of $\mathrm{Zn}\left(\mathrm{PO}_{3}-\mathrm{CH}_{2}-\mathrm{C}_{10} \mathrm{H}_{7}\right)$ and powder of $\mathrm{H}_{2} \mathrm{PO}_{3}-\mathrm{CH}_{2}-\mathrm{C}_{10} \mathrm{H}_{7}$ with a SETERAM TAG 92 apparatus, under air atmosphere, at a heating rate of $3{ }^{\circ} \mathrm{C} / \mathrm{min}$, from room temperature to $1000{ }^{\circ} \mathrm{C}$.

Scanning Electron Microscopy: The scanning electron microscopy (SEM) characterization was performed with a Carl Zeiss SUPRA 55 instrument, with the raw samples having gold metallization.

Absorbance Spectra: Absorbance spectra were recorded with a Perkin-Elmer Lambda 1050 UV/Vis spectrophotometer in specular transmittance mode in normal incidence. Samples were constituted by compound powder stacked between two suprasi ${ }^{\mathrm{TM}}$ glass slides from Hellma Analytics. Absorbance $(A)$ was calculated from measured Transmittance $(T)$ by means of the formula: $A=\log (1 / T)$.

\section{Optical Spectroscopy}

Continuous wave $(\mathrm{CW})$ photoluminescence $(\mathrm{PL})$ measurements were carried out at room temperature with a Crylas FQCW266 excitation laser emitting at $266 \mathrm{~nm}$, with an average power of $27 \mathrm{~mW}$, an incident angle of $45^{\circ}$, on a beam spot size of about $1 \mathrm{~mm}^{2}$, and 
chopped at $3.00 \mathrm{~Hz}$ for 1-naphthylmethylphosphonic acid and for $\mathrm{Zn}\left(\mathrm{PO}_{3}-\mathrm{CH}_{2}-\mathrm{C}_{10} \mathrm{H}_{7}\right)$. Emitted photons were collected into a light cone of $28^{\circ}$, by means of a set of lenses and a Horiba Jobin-Yvon Triax 180 monochromator. The detection was ensured by a R5108 Hamamatsu photomultiplier tube connected to a SR830 lock-in amplifier, referenced at the excitation light-chopper frequency. The 1-naphthylmethylphosphonic acid and phosphonate $\mathrm{Zn}\left(\mathrm{PO}_{3}-\mathrm{CH}_{2}-\right.$ $\left.\mathrm{C}_{10} \mathrm{H}_{7}\right) \mathrm{PL}$ spectra were measured on powder or single crystals stacked between two quartz suprasi ${ }^{\mathrm{TM}}$ glass slides from Hellma Analytics. For PL spectrum from 300 to $500 \mathrm{~nm}$ : laser excitation: $266 \mathrm{~nm}$; power density: $27 \mathrm{~mW} / \mathrm{mm}^{2}$; gratings with 900 slits per $\mathrm{mm}$ blazed at $850 \mathrm{~nm}$; chopping frequency: $3 \mathrm{~Hz}$. For PL spectrum from 575 to $800 \mathrm{~nm}$ : laser excitation: $266 \mathrm{~nm}$; power density: $23 \mathrm{~mW} / \mathrm{mm}^{2}$; gratings with 900 slits per $\mathrm{mm}$ blazed at $850 \mathrm{~nm}$; chopper frequency: $3 \mathrm{~Hz}$; long-pass filter with cut-on wavelength at $450 \mathrm{~nm}$.

Continuous wave (CW) photoluminescence in excitation (PLE) measurements were carried out at room temperature using an in-house developed setup. Specifically, the PL spectroscopic setup included a Lot-Oriel $1 \mathrm{~kW}$ Xenon lamp connected to an OMNI300 monochromator used as a tunable light source. The PL spectra were recorded with a Hamamatsu (R5108) photomultiplier tube, after dispersion of the PL spectroscopic signal by a MSH 300 OMNI monochromator. The detection system was locked in with a SR830 amplifier referenced at excitation light-beam chopping frequency. The PLE spectra obtained were corrected by the lamp emission intensity in the PLE case. The photoluminescence decay times were recorded using a time-resolved photoluminescence in-house setup, composed of a Surelite EX and an OPO Horizon II from Continuum as a tunable source, providing a FWHM 5 ns pulse at different wavelengths. The detection was realized by means of an Oriel $1 / 4 \mathrm{~m}$ monochromator and a Hamamatsu PMT R3896 detector. The room-temperature decay-time measurements were performed at an excitation wavelength of $266 \mathrm{~nm}$; the pulse energy was $1 \mathrm{~mJ}$ at a $10 \mathrm{~Hz}$ repetition rate. The data were acquired with a Tektronix TDS3032B oscilloscope and were recorded with a computer using a Labview homemade program.

CrystalExplorer Program: The CrystalExplorer program ${ }^{[61]}$ was used to generate the Hirshfeld surfaces (HS). The latter were calculated in very high resolution, with a standard void cluster mode (i.e., unit cell $+5 \AA$ ) and an isovalue of $0.002 \mathrm{e} \mathrm{au}^{-3}$. Besides, this program was used to generate fingerprint plots that showed any pair-atom contact types within the structures from the " $d_{i}-d e$ " data points, which represented the distances from an atom inside the molecule itself to the HS or from the HS to another molecule, respectively.

Crystal Growth of 1-Naphthylmethylphosphonic Acid: The organic precursor 1-naphthylmethylphosphonic acid $\mathrm{H}_{2} \mathrm{PO}_{3}-\mathrm{CH}_{2}-$ $\mathrm{C}_{10} \mathrm{H}_{7}$ was commercially purchased in powder form. The crystal growth of the latter was performed by microwave-hydrothermal synthesis at $120^{\circ} \mathrm{C}$. A polytetrafluoroethylene (PTFE) liner was filled with $400 \mathrm{mg}$ of 1-naphthylmethylphosphonic acid $\mathrm{H}_{2} \mathrm{PO}_{3}-\mathrm{CH}_{2}-$ $\mathrm{C}_{10} \mathrm{H}_{7}$ dissolved in $15 \mathrm{~mL}$ of distilled water. Then, the liner was coated with a carbon-fiber shell and placed into a microwave furnace CEM Corp. model MARS-6. The latter was heated from room temperature to $120^{\circ} \mathrm{C}$ within $2 \mathrm{~h}$, kept at $120^{\circ} \mathrm{C}$ for $1 \mathrm{~h}$, and finally, was naturally cooled to room temperature. After filtration, the resulting product, obtained as white needle-shape crystallites, was washed with distilled water and then dried in air.

Synthesis of 1-Naphthylmethylzinc Phosphonate: All reagents were commercially obtained and were used without prior purification in hydrothermal synthesis using the following process. In a $25 \mathrm{~mL}$ polytetrafluoroethylene (PTFE) liner, an equimolar mixture of zinc nitrate hexahydrate $\mathrm{Zn}\left(\mathrm{NO}_{3}\right)_{2} \cdot 6 \mathrm{H}_{2} \mathrm{O}(0.067 \mathrm{~g}, 0.225 \mathrm{mmol})$, phosphonic acid $\mathrm{H}_{2} \mathrm{PO}_{3}-\mathrm{CH}_{2}-\mathrm{C}_{10} \mathrm{H}_{7}(0.050 \mathrm{~g}, 0.225 \mathrm{mmol})$ (Figure 1a), and urea $\left(\mathrm{NH}_{2}\right)_{2} \mathrm{CO}(0.014 \mathrm{~g}, 0.225 \mathrm{mmol})$ were dissolved in distilled water $(15 \mathrm{~mL})$. Then, the liner was transferred to a Berghof DAB-2 pressure digestive vessel and heated from room temperature to $160{ }^{\circ} \mathrm{C}$ over $20 \mathrm{~h}$, then was further heated for $24 \mathrm{~h}$, and was finally cooled to room temperature over $20 \mathrm{~h}$. After vacuum filtration, the final product, $\mathrm{Zn}\left(\mathrm{PO}_{3}-\mathrm{CH}_{2}-\mathrm{C}_{10} \mathrm{H}_{7}\right)$, obtained as transparent platelet-shaped single crystals, was washed with distilled water, rinsed with ethanol, and finally dried under an air atmosphere. Yield: $80 \% . \mathrm{C}_{11} \mathrm{H}_{9} \mathrm{O}_{3} \mathrm{PZn}$ (285.52): Elemental analysis: $\mathrm{C} 46.26, \mathrm{H}$ 3.18; found C 46.16, H 2.95 .

Scanning Electron Microscopy (SEM): As observed by SEM characterization, the hybrid material $\mathrm{Zn}\left(\mathrm{PO}_{3}-\mathrm{CH}_{2}-\mathrm{C}_{10} \mathrm{H}_{7}\right)$ was composed of oblong-shape crystallites, with an average length of $325 \mu \mathrm{m}$, width of $30 \mu \mathrm{m}$, and a thickness of $5 \mu \mathrm{m}$ (Figure S1).

Thermogravimetric Analysis (TGA): The recorded curve obtained by thermogravimetric analysis confirmed the absence of water molecules in the structure of $\mathrm{Zn}\left(\mathrm{PO}_{3}-\mathrm{CH}_{2}-\mathrm{C}_{10} \mathrm{H}_{7}\right)$ (Figure S2). Besides, it highlighted its remarkable thermal stability from room temperature to $460{ }^{\circ} \mathrm{C}$, as shown by the presence of a plateau. Then, the mass losses of $46.85 \%$ observed from that temperature to $1000{ }^{\circ} \mathrm{C}$ corresponded to the decomposition of the organic moiety until the formation of the zinc pyrophosphate $\mathrm{Zn}_{2} \mathrm{P}_{2} \mathrm{O}_{7}$. This final residue was clearly identified by X-ray diffraction and was in good agreement with the percentage of mass still present in the TGA residual powder: $53.15 \%$ (theoretical value: $53.36 \%$ ).

\section{Acknowledgments}

We thank the Agence Nationale de la Recherche [contract No. ANR-14-CE07-0004-01 (HYMN)] for financial support. The authors also express their grateful acknowledgment, for technical support, to Sylvie Collin from the CRISMAT laboratory.

Keywords: Zinc · Phosphonates · Naphthalene · Luminescence · Aggregation

[1] a) C. W. Tang, S. A. VanSlyke, Appl. Phys. Lett. 1987, 51, 913-915; b) N. Thejo Kalyani, S. J. Dhoble, Renewable Sustainable Energy Rev. 2012, 16, 2696-2723.

[2] Z. Wu, D. Ma, Mater. Sci. Eng. R 2016, 107, 1-42.

[3] Z. Wang, W. Liu, C. Xu, B. Ji, C. Zheng, X. Zhang, Opt. Mater. 2016, 58, 260-267.

[4] J. Lee, C. Jeong, T. Batagoda, C. Coburn, M. E. Thompson, S. R. Forrest, Nat. Commun. 2017, 8, 15566.

[5] J. B. Birks, Rep. Prog. Phys. 1975, 38, 903.

[6] E. C. Lim, Acc. Chem. Res. 1987, 20, 8-17.

[7] M. Pabst, B. Lunkenheimer, A. Köhn, J. Phys. Chem. C 2011, 115, 83358344.

[8] S. Reineke, M. A. Baldo, Sci. Rep. 2014, 4, 3797.

[9] J. Kuijt, F. Ariese, U. A. T. Brinkman, C. Gooijer, Anal. Chim. Acta 2003, $488,135-171$.

[10] M. D. Allendorf, C. A. Bauer, R. K. Bhakta, R. J. T. Houk, Chem. Soc. Rev. 2009, 38, 1330-1352.

[11] G. A. Crosby, R. G. Highland, K. A. Truesdell, Coord. Chem. Rev. 1985, 64, 41-52.

[12] R. G. Highland, J. G. Brummer, G. A. Crosby, J. Phys. Chem. 1986, 90, 1593-1598.

[13] K. J. Jordan, W. F. Wacholtz, G. A. Crosby, Inorg. Chem. 1991, 30, 45884593.

[14] D. Sun, D. J. Collins, Y. Ke, J.-L. Zuo, H.-C. Zhou, Chem. Eur. J. 2006, 12, 3768-3776. 
[15] W.-P. Wu, Y.-Y. Wang, Y.-P. Wu, J.-Q. Liu, X.-R. Zeng, Q.-Z. Shi, S.-M. Peng, CrystEngComm 2007, 9, 753-757.

[16] M.-X. Li, Z.-X. Miao, M. Shao, S.-W. Liang, S.-R. Zhu, Inorg. Chem. 2008, $47,4481-4489$.

[17] X.-M. Ouyang, Z.-W. Li, T. Okamura, Y.-Z. Li, W.-Y. Sun, W.-X. Tang, N. Ueyama, J. Solid State Chem. 2004, 177, 350-360.

[18] Y. Xu, D. Yuan, B. Wu, L. Han, M. Wu, F. Jiang, M. Hong, Cryst. Growth Des. 2006, 6, 1168-1174.

[19] R.-Q. Zhong, R.-Q. Zou, M. Du, L. Jiang, T. Yamada, G. Maruta, S. Takeda, Q. Xu, CrystEngComm 2008, 10, 605-613.

[20] M. Du, X.-J. Jiang, X.-J. Zhao, H. Cai, J. Ribas, Eur. J. Inorg. Chem. 2006, 2006, 1245-1254.

[21] L. Han, D. Yuan, B. Wu, C. Liu, M. Hong, Inorg. Chim. Acta 2006, 359, 2232-2240.

[22] G. B. Hix in Metal Phosphonate Chemistry: From Synthesis to Applications (Eds.: A. Clearfield, K. Demadis), Royal Society of Chemistry, Cambridge, 2011, pp. 525-550.

[23] J.-M. Rueff, V. Caignaert, S. Chausson, A. Leclaire, C. Simon, O. Perez, L. Le Pluart, P.-A. Jaffrès, Eur. J. Inorg. Chem. 2008, 2008, 4117-4125.

[24] J.-M. Rueff, V. Caignaert, A. Leclaire, C. Simon, J.-P. Haelters, P.-A. Jaffrès, CrystEngComm 2009, 11, 556-559.

[25] J.-M. Rueff, O. Perez, V. Caignaert, G. Hix, M. Berchel, F. Quentel, P.-A. Jaffrès, Inorg. Chem. 2015, 54, 2152-2159.

[26] J.-M. Rueff, N. Barrier, S. Boudin, V. Dorcet, V. Caignaert, P. Boullay, G. B. Hix, P.-A. Jaffrès, Dalton Trans. 2009, 10614-10620.

[27] R. Fu, S. Hu, X. Wu, Dalton Trans. 2009, 9440-9445.

[28] P.-F. Wang, Y. Duan, D.-K. Cao, Y.-Z. Li, L.-M. Zheng, Dalton Trans. 2010, 39, 4559-4565.

[29] W. Dan, X. Liu, M. Deng, Y. Ling, Z. Chen, Y. Zhou, Inorg. Chem. Commun. 2013, 37, 93-96.

[30] C. Heering, B. Francis, B. Nateghi, G. Makhloufi, S. Lüdeke, C. Janiak, CrystEngComm 2016, 18, 5209-5223.

[31] R. Fu, S. Hu, X. Wu, Cryst. Growth Des. 2015, 15, 5021-5027.

[32] F. Tong, Z.-G. Sun, K. Chen, Y.-Y. Zhu, W.-N. Wang, C.-Q. Jiao, C.-L. Wang, C. Li, Dalton Trans. 2011, 40, 5059-5065.

[33] R. Fu, S. Hu, X. Wu, CrystEngComm 2013, 15, 8937-8940.

[34] X. Li, Y. Sun, Y. Chen, Z. Zhou, Z. Du, Struct. Chem. 2012, 23, 91-96.

[35] Y.-S. Ma, X.-Y. Tang, W.-Y. Yin, B. Wu, F.-F. Xue, R.-X. Yuan, S. Roy, Dalton Trans. 2012, 41, 2340-2345.

[36] R. Singleton, J. Bye, J. Dyson, G. Baker, R. M. Ranson, G. B. Hix, Dalton Trans. 2010, 39, 6024-6030.

[37] A. Clearfield, K. Demadis (Eds.), Metal Phosphonate Chemistry: From Synthesis to Applications, Royal Society of Chemistry, Cambridge, 2011.

[38] J. Krausko, J. K. Malongwe, G. Bičanová, P. Klán, D. Nachtigallová, D. Heger, J. Phys. Chem. A 2015, 119, 8565-8578.

[39] J. Ferguson, L. W. Reeves, W. G. Schneider, Can. J. Chem. 1957, 35, 11171136.

[40] G. A. George, G. C. Morris, J. Mol. Spectrosc. 1968, 26, 67-71.

[41] H. Sponer, G. P. Nordheim, Discuss. Faraday Soc. 1950, 9, 19-26.

[42] W. Majewski, W. L. Meerts, J. Mol. Spectrosc. 1984, 104, 271-281.

[43] A. Bree, T. Thirunamachandran, Mol. Phys. 1962, 5, 397-405.

[44] J. R. Cardinal, P. Mukerjee, J. Phys. Chem. 1978, 82, 1614-1620.

[45] D. P. Craig, L. E. Lyons, J. R. Walsh, Mol. Phys. 1961, 4, 97-112.

[46] O. Schnepp, Annu. Rev. Phys. Chem. 1963, 14, 35-60.

[47] R. Passerini, I. G. Ross, J. Chem. Phys. 1954, 22, 1012-1016.
[48] G. Grabner, K. Rechthaler, B. Mayer, G. Köhler, K. Rotkiewicz, J. Phys. Chem. A 2000, 104, 1365-1376.

[49] A. Köhler, A. L. T. Khan, J. S. Wilson, C. Dosche, M. K. Al-Suti, H. H. Shah, M. S. Khan, J. Chem. Phys. 2012, 136, 094905.

[50] E. B. Priestley, A. Haug, J. Chem. Phys. 1968, 49, 622-629.

[51] L.-D. Li, W.-Q. Long, A.-J. Tong, Spectrochim. Acta Part A 2001, 57, 12611270.

[52] S. Hashimoto, M. Yamaji, Phys. Chem. Chem. Phys. 2008, 10, 3124-3130.

[53] N. K. Al-Rasbi, C. Sabatini, F. Barigelletti, M. D. Ward, Dalton Trans. 2006, 4769-4772.

[54] L. Li, Y. Zhao, Y. Wu, A. Tong, Talanta 1998, 46, 1147-1154.

[55] M. A. Omary, O. Elbjeirami, C. S. P. Gamage, K. M. Sherman, H. V. R. Dias, Inorg. Chem. 2009, 48, 1784-1786.

[56] B. D. Wagner, G. J. McManus, B. Moulton, M. J. Zaworotko, Chem. Commun. 2002, 2176-2177.

[57] G. J. McManus, J. J. Perry, M. Perry, B. D. Wagner, M. J. Zaworotko, J. Am. Chem. Soc. 2007, 129, 9094-9101.

[58] J. Cornil, D. A. dos Santos, X. Crispin, R. Silbey, J. L. Brédas, J. Am. Chem. Soc. 1998, 120, 1289-1299.

[59] T. Förster, Angew. Chem. Int. Ed. Engl. 1969, 8, 333-343; Angew. Chem. $1969,81,364$

[60] T. D. M. Bell, S. V. Bhosale, C. M. Forsyth, D. Hayne, K. P. Ghiggino, J. A. Hutchison, C. H. Jani, S. J. Langford, M. A.-P. Lee, C. P. Woodward, Chem. Commun. 2010, 46, 4881-4883.

[61] S. K. Wolff, D. J. Grimwood, J. J. McKinnon, M. J. Turner, D. Jayatilaka, M. A. Spackman, CrystalExplorer Program, University of Western Australia, 2012.

[62] a) M. A. Spackman, D. Jayatilaka, CrystEngComm 2009, 11, 19-32; b) J. J. McKinnon, M. A. Spackman, A. S. Mitchell, Acta Crystallogr., Sect. B: Struct. Sci. 2004, 60, 627-668.

[63] Q. Li, Z. Li, Adv. Sci. 2017, 4, 1600484.

[64] M. Yanagidate, K. Takayama, M. Takeuchi, J. Nishimura, H. Shizuka, J. Phys. Chem. 1993, 97, 8881-8888.

[65] F. Márquez, C. M. Zicovich-Wilson, A. Corma, E. Palomares, H. García, J. Phys. Chem. B 2001, 105, 9973-9979.

[66] M. Baroncini, G. Bergamini, P. Ceroni, Chem. Commun. 2017, 53, 20812093

[67] H. Kar, S. Ghosh, Chem. Commun. 2016, 52, 8818-8821.

[68] H. Kar, D. W. Gehrig, N. K. Allampally, G. Fernández, F. Laquai, S. Ghosh, Chem. Sci. 2016, 7, 1115-1120.

[69] X. Fang, H. Ke, L. Li, M.-J. Lin, Dyes Pigm. 2017, 145, 469-475.

[70] X. Cao, L. Meng, Z. Li, Y. Mao, H. Lan, L. Chen, Y. Fan, T. Yi, Langmuir 2014, 30, 11753-11760.

[71] G. Feng, R. T. K. Kwok, B. Z. Tang, B. Liu, Appl. Phys. Rev. 2017, 4, 021307.

[72] J. Mei, N. L. C. Leung, R. T. K. Kwok, J. W. Y. Lam, B. Z. Tang, Chem. Rev. 2015, 115, 11718-11940.

[73] N. V. Ghule, D. D. La, R. S. Bhosale, M. Al Kobaisi, A. M. Raynor, S. V. Bhosale, S. V. Bhosale, ChemistryOpen 2016, 5, 157-163.

[74] P. M. Beaujuge, J. M. J. Fréchet, J. Am. Chem. Soc. 2011, 133, 2000920029

[75] J. Mei, Y. Diao, A. L. Appleton, L. Fang, Z. Bao, J. Am. Chem. Soc. 2013, $135,6724-6746$

[76] G. M. Sheldrick, Acta Crystallogr., Sect. C: Struct. Chem. 2015, 71, 3-8. 
Aggregation-Induced Emission

C. Bloyet, J.-M. Rueff,* J. Cardin,

V. Caignaert, J.-L. Doualan, J.-F. Lohier,

P.-A. Jaffrès, B. Raveau* 1-10

Excimer and Red Luminescence Due to Aggregation-Induced Emission in Naphthalene Based Zinc Phosphonate

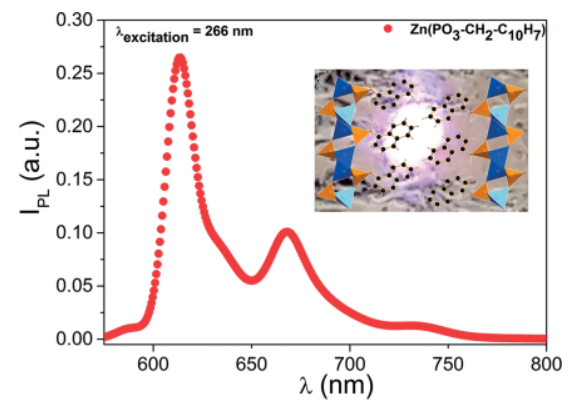

The luminescence and structure of a naphthalene based zinc phosphonate $\mathrm{Zn}\left(\mathrm{PO}_{3}-\mathrm{CH}_{2}-\mathrm{C}_{10} \mathrm{H}_{7}\right)$, which displays excimer formation and red emission due to aggregation-induced emission (AIE), is presented. 